\title{
Assessment of the efficacy of ofatumumab in patients with chronic lymphocytic leukaemia treated in the Department of Haematooncology and Bone Marrow Transplantation of the Medical University in Lublin - Prelimary results
}

\author{
Ewa Wąsik-Szczepanek ${ }^{1}$, Agnieszka Szymczyk ${ }^{1,2}$, Małgorzata Kowal', Adam Nogalski ${ }^{3}$, Marek Hus ${ }^{1}$ \\ ${ }^{1}$ Department of Haematooncology and Bone Marrow Transplantation, Medical University \\ 2 Independent Transplantology Unit, Medical University of Lublin, Lublin \\ ${ }^{3}$ Department of Trauma Surgery and Emergency Medicine, Medical University of Lublin, Poland \\ Wąsik-Szczepanek E, Szymczyk A, Kowal M, Nogalski A, Hus M. Assessment of the efficacy of ofatumumab in patients with chronic lymphocytic \\ leukaemia treated in the Department of Haematooncology and Bone Marrow Transplantation of the Medical University in Lublin - Prelimary \\ results. Ann Agric Environ Med. 2018; 25(1): 56-59. doi: 10.5604/12321966.1233571
}

\begin{abstract}
Introduction. Despite significant recent advances in the treatment of chronic lymphocytic leukaemia (CLL), most cases of the disease are still incurable. Treatment with monoclonal antibodies, such as ofatumumab, is one of the new therapeutic options.

Objective. Retrospective analysis of the efficacy of ofatumumab in patients with chronic lymphocytic leukaemia (CLL) treated in the Haematooncology and Bone Marrow Transplantation Department of the Medical University of Lublin, Poland, during 2011-2013.

Materials and method. The analysis included 5 patients ( 3 women and 2 men), aged 47-65, with Rai stage II-IV CLL, after a few lines of treatment. Three patients received ofatumumab in monotherapy and 2 patients received ofatumumab in combination with cyclophosphamide (50 mg/day) and dexamethasone ( $40 \mathrm{mg} /$ day). All patients included in the study were diagnosed with an active form of leukaemia with symptoms such as lymphocytosis or massive lymphadenopathy.

Results. All patients responded to the treatment. Within the first 8 weeks of the treatment, levels of white blood cells returned to normal in patients with baseline lymphocytosis (3 patients). An increase in platelet levels was reported in 3 patients. Haemoglobin levels were higher or comparable to the baseline values in all studied patients after the completion of immunotherapy. In the patient with massive lymphadenopathy and hepato- and splenomegaly, the size of the lymph nodes, spleen and liver decreased and neutrophil levels increased. Time of progression was 5-12 months, and in one patient partial remission has been maintained. The treatment was well-tolerated in most cases. Asymptomatic neutropenia and an infection with Candida glabrata were observed.

Conclusions. Ofatumumab may be a new and safe therapeutic option for patients with CLL after a few lines of treatment.
\end{abstract}

Key words

chronic lymphocytic leukemia, ofatumumab, monoclonal antibodies, immunotherapy

\section{INTRODUCTION}

Despite significant recent advances in the treatment of chronic lymphocytic leukaemia (CLL), such as the introduction of purine analogues and monoclonal antibodies, most cases of the disease are still incurable. Allogenic transplantation of haematopoietic cells, which is an opportunity for a complete cure, can be used only in a small percentage of patients. For this reason, it is extremely important to use new drugs and therapeutic regimens which are available to a large number of patients with CLL, and which offer an opportunity for increased overall survival (OS). Currently, the FCR (Fludarabine, Cyclophosphamide, Rituximab) regimen is considered the gold standard in the first-line treatment of CLL in patients in overall good condition $[1,2]$. Research

Address for correspondence: Agnieszka Szymczyk, Department of Hematooncology and Bone Marrow Transplantation Medical University of Lublin, ul. Staszica 11, 20-081 Lublin, Poland.

E-mail: agnieszka.szymczyk.med@wp.pl

Received: 3 August 2015; accepted: 31 August 2016; first published on February 2017 has shown that the introduction of FCR has beneficial effects on the number of complete remissions (CR) and overall survival (OS). Rituximab, the first widely-used anti-CD20 monoclonal antibody, is an important part of this regimen. Recently, new monoclonal antibodies, such as Camptah- $1 \mathrm{H}$ (anti-CD52), ofatumumab and obinutuzumab (both directed against CD20), have been introduced. However, the treatment of patients with relapsed and refractory types of CLL is still a difficult and often unresolved clinical problem $[1,2,3]$.

\section{OBJECTIVE}

The objective of this study is a retrospective analysis of the efficacy of ofatumumab in patients with chronic lymphocytic leukaemia (CLL) treated in the Haematooncology and Bone Marrow Transplantation Department of the Medical University in Lublin, Poland, during 2011-2013. 


\section{MATERIALS AND METHOD}

The analysis included 5 patients diagnosed with chronic lymphocytic leukaemia during 1995-2007, Rai stage II -IV and after a few lines of treatment. The study group included 3 women and 2 men, all aged 47-65. Clinical characteristics are presented in Tables 1-3. They were all diagnosed with the active form of leukaemia that required treatment. Three patients (Nos. 1, 3 and 4) received ofatumumab due to lymphocytosis, whereas 2 other patients required treatment because of lymphadenopathy with hepatosplenomegaly (Nos.

Table 1. Clinical characteristics of patients treated with ofatumumab at the outset of therapy

\begin{tabular}{lccccc}
\hline & Gender & $\begin{array}{c}\text { Age } \\
\text { (years) }\end{array}$ & $\begin{array}{c}\text { Rai clinical } \\
\text { stage }\end{array}$ & $\begin{array}{c}\text { Disease duration } \\
\text { (months) }\end{array}$ & $\begin{array}{c}\text { N0. of lines } \\
\text { of treatment }\end{array}$ \\
\hline Patient No. 1 & M & 65 & III & 196 & 9 \\
\hline Patient No. 2 & F & 47 & III & 122 & 7 \\
\hline Patient No. 3 & F & 51 & II & 66 & 3 \\
\hline Patient No. 4 & F & 57 & IV & 171 & 6 \\
\hline Patient No. 5 & M & 50 & II & 60 & 4 \\
\hline
\end{tabular}

Table 2. Peripheral blood count and organ abnormalities at the outset of ofatumumab treatment

\begin{tabular}{lcccc}
\hline & WBC (K/ul) & LYMPH (K/ul) & $\begin{array}{c}\text { hepato-, } \\
\text { splenomegaly }\end{array}$ & lymphadenopathy \\
\hline Patient No.1 & 259.01 & 245.14 & yes & yes \\
\hline Patient No. 2 & 4.89 & 1.99 & yes & yes \\
\hline Patient No. 3 & 153.40 & 111.70 & yes & yes \\
\hline Patient No. 4 & 45.06 & 33.22 & yes & yes \\
\hline Patient No. 5 & 1.14 & 0.32 & yes & yes \\
\hline
\end{tabular}

Table 3. ZAP-70 and CD38 expression and genetic aberrations at the outset of ofatumumab treatment

\begin{tabular}{lcccl}
\hline & ZAP70 & CD38 & del(11q) & del(17p) \\
\hline Patient No. 1 & negative & negative & negative & negative \\
\hline Patient No. 2 & no data & no data & negative & negative \\
\hline Patient No. 3 & negative & positive & negative & negative \\
\hline Patient No. 4 & positive & positive & negative & negative \\
\hline Patient No. 5 & positive & positive & negative & negative \\
\hline
\end{tabular}

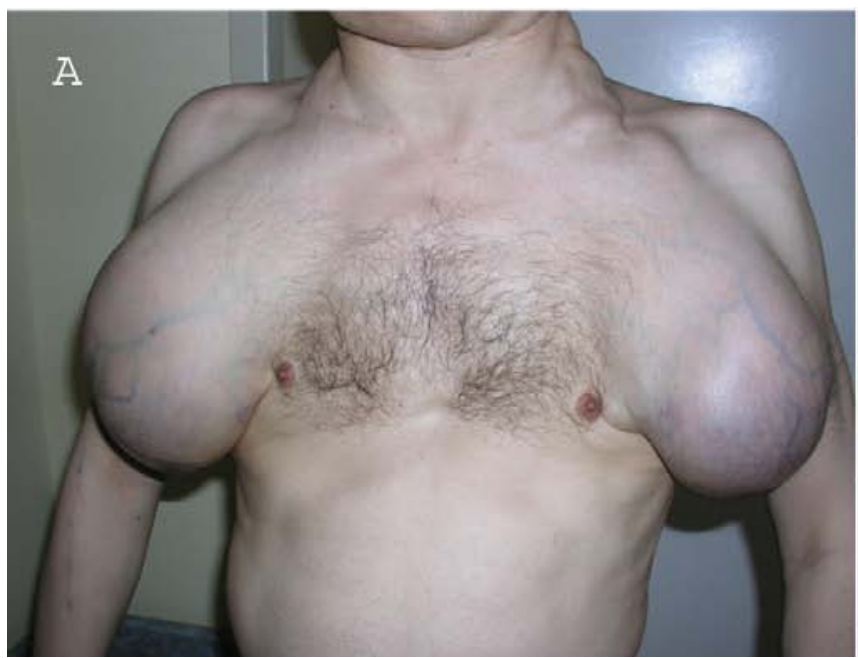

2 and 5). Before ofatumumab treatment, patients had been administered a few lines of chemotherapy. Fludarabine was a component of at least one of them.

In patients 1,2 and 3, ofatumumab was used in monotherapy. The initial dose was $300 \mathrm{mg}$; subsequent doses were 2,000 mg. The regimen included 8 infusions administered every week for 8 consecutive weeks. After this time, ofatumumab was administered as a single dose of $2,000 \mathrm{mg} / \mathrm{month}$. Patient No. 1 received 11, patient No 2-7 and patient No. 3-12 infusions of monoclonal antibody, according to the treatment regimen described above.

Patients 4 and 5 received ofatumumab in combination with cyclophosphamide (50 mg/day) and dexamethasone (40 mg/day) on days $1-4,8-11,15-18$ and $22-25$ of every 28 day treatment cycle. In this group of patients, ofatumumab was administered on days $1,8,15$ and 22 of each 28-day $(1,000 \mathrm{mg} /$ dose $)$ treatment cycle. Both patients received 6 full cycles of the treatment.

All patients were administered premedication (paracetamol, clemastine and hydrocortisone or dexamethasone at a body mass-dependent dose) before the infusion of ofatumumab.

\section{RESULTS}

All patients responded to the treatment. Two patients, Nos. 1 and 5 , achieved partial remission (PR) and 3 patients (Nos. 2, 3 and 4) reached stable disease (SD). Lymphocyte counts significantly decreased in patients with initial lymphocytosis (Nos. 1, 3 and 4) (Fig. 1; Tab. 4).

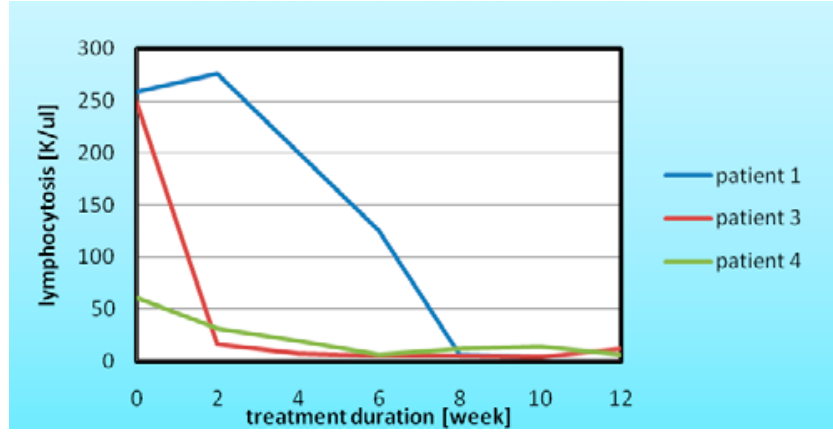

Figure 1. Lymphocyte counts in patients 1, 3 and 4, before, during and after ofatumumab treatment

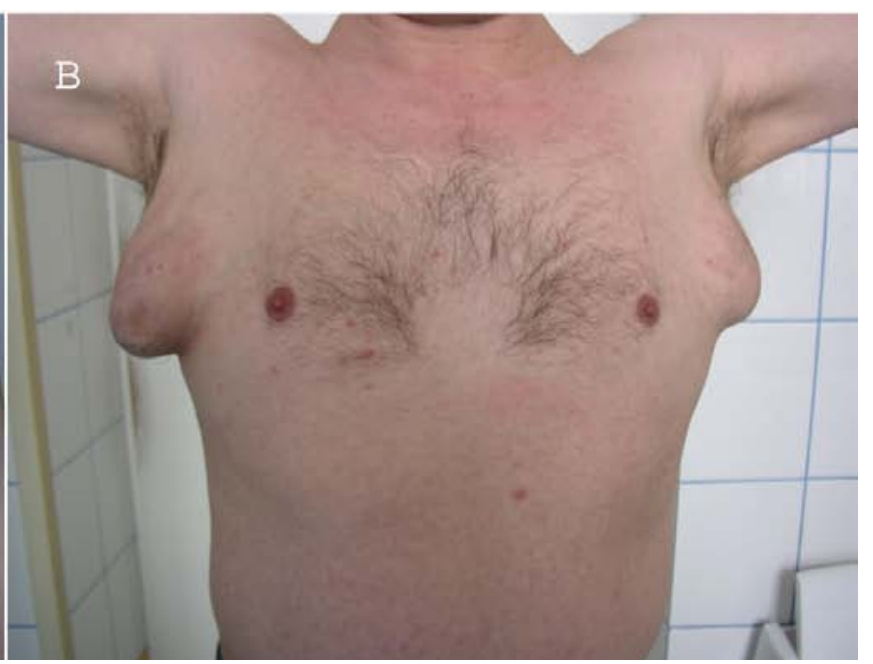

Figure 2. A: Lymph nodes of the patient no 5 before ofatumumab treatment. B: Lymph nodes of the same patient after ofatumumab treatment 
Table 4. Haemoglobin, lymphocyte and platelet counts in the studied group before and after ofatumumab treatment.

\begin{tabular}{lccccc}
\hline & $\begin{array}{c}\text { Patient } \\
\text { No. } 1\end{array}$ & $\begin{array}{c}\text { Patient } \\
\text { No. } 2\end{array}$ & $\begin{array}{c}\text { Patient } \\
\text { No. } 3\end{array}$ & $\begin{array}{c}\text { Patient } \\
\text { No. } 4\end{array}$ & $\begin{array}{c}\text { Patient } \\
\text { No. 5 }\end{array}$ \\
\hline $\begin{array}{l}\text { Haemoglobin levels } \\
\text { before the treatment }\end{array}$ & $10.7 \mathrm{~g} / \mathrm{dl}$ & $10.0 \mathrm{~g} / \mathrm{dl}$ & $11.6 \mathrm{~g} / \mathrm{dl}$ & $11.7 \mathrm{~g} / \mathrm{dl}$ & $15.4 \mathrm{~g} / \mathrm{dl}$ \\
\hline $\begin{array}{l}\text { Haemoglobin levels } \\
\text { after the treatment }\end{array}$ & $13.4 \mathrm{~g} / \mathrm{dl}$ & $12.2 \mathrm{~g} / \mathrm{dl}$ & $14.9 \mathrm{~g} / \mathrm{dl}$ & $11.7 \mathrm{~g} / \mathrm{dl}$ & $16.1 \mathrm{~g} / \mathrm{dl}$ \\
\hline $\begin{array}{l}\text { Lymphocyte counts } \\
\text { before the treatment }\end{array}$ & $259.0 \mathrm{~K} / \mu \mathrm{l}$ & $4.89 \mathrm{~K} / \mu \mathrm{l}$ & $153.4 \mathrm{~K} / \mu \mathrm{l}$ & $45.06 \mathrm{~K} / \mu \mathrm{l}$ & $1.14 \mathrm{~K} / \mu \mathrm{l}$ \\
$\begin{array}{l}\text { Lymphocyte counts } \\
\text { after the treatment }\end{array}$ & $3.13 \mathrm{~K} / \mu \mathrm{l}$ & $3.42 \mathrm{~K} / \mu \mathrm{l}$ & $11.22 \mathrm{~K} / \mu \mathrm{l}$ & $3.95 \mathrm{~K} / \mu \mathrm{l}$ & $5.85 \mathrm{~K} / \mu \mathrm{l}$ \\
\hline $\begin{array}{l}\text { Platelet counts } \\
\text { before the treatment }\end{array}$ & $126.0 \mathrm{~K} / \mu \mathrm{l}$ & $111.0 \mathrm{~K} / \mu \mathrm{l}$ & $177.0 \mathrm{~K} / \mu \mathrm{l}$ & $60.0 \mathrm{~K} / \mu \mathrm{l}$ & $103.0 \mathrm{~K} / \mu \mathrm{l}$ \\
\hline $\begin{array}{l}\text { Platelet counts after } \\
\text { the treatment }\end{array}$ & $137.0 \mathrm{~K} / \mu \mathrm{l}$ & $83.0 \mathrm{~K} / \mu \mathrm{l}$ & $163.0 \mathrm{~K} / \mu \mathrm{l}$ & $102.0 \mathrm{~K} / \mu \mathrm{l}$ & $189.0 \mathrm{~K} / \mu \mathrm{l}$ \\
\hline
\end{tabular}

Platelet counts increased in patients 4 and 5 in comparison to the baseline values. Haemoglobin levels were higher or comparable to the baseline values in all studied patients after the completion of immunotherapy (Tab. 4).

In patient No. 5, who was treated with immunotherapy because of massive lymphadenopathy (Fig. 2A) and hepatoand splenomegaly, the size of the lymph nodes (Fig. 2B), spleen and liver significantly decreased.

The clinical stage of the disease was reduced in 3 patients: patient No. 1 (initially - Rai stage III, stage II - after the treatment), patient No. 4 (initially - Rai stage IV, stage III - after the treatment), patient No. 6 (initially - Rai stage II, stage I - after the treatment).

Progression-free survival, defined as the time from the initiation of ofatumumab treatment to the progression of the disease or death of a patient, was 5-12 months. In one case, partial remission has been maintained until the date of publication (Tab. 5). Overall survival (OS), understood as the time from the initiation of immunotherapy to the death of a patient, was determined for only one patient (No. 1), who

Table 5. Progression-free survival (PFS) and overall survival (OS) in patients after ofatumumab treatment

\begin{tabular}{lccccc}
\hline & $\begin{array}{c}\text { Patient } \\
\text { No.1** }\end{array}$ & $\begin{array}{c}\text { Patient } \\
\text { No. } 2^{* *}\end{array}$ & $\begin{array}{c}\text { Patient } \\
\text { No. } 3^{* *}\end{array}$ & $\begin{array}{c}\text { Patient } \\
\text { No. } 4^{* *}\end{array}$ & $\begin{array}{c}\text { Patient No. } \\
5^{* * *}\end{array}$ \\
\hline PFS (months) & 9 & 9 & 5 & 12 & - \\
\hline OS (months) & 24 & - & - & - & - \\
\hline
\end{tabular}

* patients with partial remission, with no signs of progression

** living patients

died because of the progression of leukaemia. Other patients are still being followed-up (Tab. 5).

The treatment was well-tolerated in most cases. Asymptomatic neutropenia (grade 2) and transient elevation in transaminases (Alat - grade 3) were observed in patient No 5. Administration of growth factors and hepatoprotective agents resulted in normalization of these parameters. Despite premedication, patient No 4 had infusion reactions (skin redness and rash) after every administration of ofatumumab. He required continuous use of anti-histamines. Moreover, asymptomatic infection with Candida glabrata was observed during the sixth cycle of the treatment.

\section{DISCUSION}

Precise identification of genetic and immunological profile of patients with chronic lymphocytic leukaemia, and thus the assessment of risk factors, helps to customize the treatment. At the same time, despite significant advances in the therapy of chronic lymphocytic leukaemia (CLL), most cases of the disease are still incurable. The combination of monoclonal antibodies with chemotherapy (FCR regimen) leads to a large number of complete remissions and higher overall survival rates in many patients. However, patients refractory to purine analogues, especially fludarabine, who constitute a group with an extremely unfavourable prognosis, are still an important and unresolved problem [4].

Available therapeutic option are usually limited due to the advanced age of patients, concomitant diseases and prior cytostatic treatment. One of the retrospective, singlecentre studies proved low efficacy of various, also aggressive, treatment options. The response rate was only $23 \%$, while the risk of infectious complications was high for $54 \%$ of the patients. Monotherapy with rituximab was one of the available options, but it proved to be disappointing due to the lack of response and median OS of only 6 months [5].

Attempts to solve this difficult issue included the treatment with ofatumumab, a new anti-CD-20 monoclonal antibody. It is believed that this antibody is more active than rituximab because it binds to a different epitope which includes both the large and small extracellular domains of CD20, and it has slower dissociation rate $[6,7]$.

In 2009, 2 clinical trials were especially important for the FDA approval of ofatumumab in the therapy of previously treated CLL patients. In one of the studies, Coiffier et al. treated 33 patients with refractory/relapsed CLL with ofatumumab in monotherapy and obtained a partial response (PR) in $48 \%$ of patients. Median progression-free survival was just over 3 months (106 days) [8]. The other study included patients with relapsed CLL who had been treated previously with fludarabine and alemtuzumab, and those with bulky lymphadenopathy. The response rate was 58 and $47 \%$ (complete remission was achieved in one case) and PFS was 5.7 and 5.9 months, respectively [9].

These results, favourable in terms of the efficacy of ofatumumab in the monotherapy of patients with CLL and poor prognosis, were not replicated by Moreno et al. The response rate in this case was only $22 \%$, PFS was 5 months and OS - 11 months [10].

Although the group of patients presented in this paper was small, it is worth noting that all of them responded to the treatment with ofatumumab. The best result (PR) was achieved in patient No. 1, whose morphological parameters significantly improved, despite the advanced stage and longterm course of the disease and the largest number of prior therapies. In patient No. 5, a spectacular improvement of lymphadenopathy was observed, which proves the efficacy of ofatumumab in patients with bulky CLL, which had been reported previously by Wierda et al. [11]. In this case, ofatumumab was combined with cyclophosphamide and dexamethasone, which probably had a positive effect on the treatment results. Synergistic action of ofatumumab and dexamethasone with high response rates and good tolerability were also reported by Castro et al and Doubek et al. [12]. Attempts are now being made to combine ofatumumab with other drugs, such as bendamustine [13] or lenalidomide [14]. 
The treatment was well-tolerated by the patients presented in this paper. There was only one asymptomatic ganulocytopaenia (grade 2), transient elevation in transaminases (grade 3 ) and asymptomatic infection with Candida glabrata. One patient had an infusion reaction (skin redness and rash).

Cytometric analyses have shown that ofatumumab probably plays a role in the rapid and prolonged depletion of circulating normal B lymphocytes, which may lead to cytopenia and infectious complications [8]. Safety and good tolerability of ofatumumab have also been confirmed in studies by other authors $[8,9]$. Interestingly, Österborg et al. have proved the high efficacy of ofatumumab retreatment in patients who initially responded to the therapy and then relapsed.

\section{CONCLUSIONS}

Ofatumumab may be a new and safe therapeutic option for patients with poor prognosis after a few lines of the treatment. Beneficial effects of ofatumumab may be increased by its combination with other drugs, such as dexamethasone and cyclophosphamide. Further research is needed to confirm these hypotheses.

\section{Contribution statement}

EWSz, ASz and MH conceived the idea for the study. EWSZ, $\mathrm{MH}$ and $\mathrm{MK}$ were involved in data collection. ASz, EWSz, $\mathrm{MK}, \mathrm{AN}$ and $\mathrm{MH}$ analysed the data and reviewed the manuscript

\section{Conflict of interest}

None declared.

\section{REFERENCES}

1. Gupta IV, Jewell RC. Ofatumumab, the first human anti-CD20 monoclonal antibody for the treatment of $\mathrm{B}$ cell hematologic malignancies. Ann N Y Acad Sci. 2012; 1263: 43-56.

2. Dyer MJ. Safety and efficacy of ofatumumab in patients with fludarabine and alemtuzumab refractory chronic lymphocytic leukaemia. Ther Adv Hematol. 2012; 3(4): 199-207.

3. Dudziński M. Miejsce ofatumumabu w terapii chłoniaków B-komórkowych. Hematologia 2011; 2(3): 246-255.

4. Keating MJ, O’Brien S, Kontoyiannis D, Plunkett W, Koller C, Beran M, Lerner S, Kantarjian H. Results of first salvage therapy for patients refractory to a fludarabine regimen in chronic lymphocytic leukemia. Leuk Lymphoma. 2002; 43(9): 1755-1762.
5. Tam CS, O’Brien S, Lerner S, Khouri I, Ferrajoli A, Faderl S, Browning M, Tsimberidou AM, Kantarjian H, Wierda WG. The natural history of fludarabine-refractory chronic lymphocytic leukemia patients who fail alemtuzumab or have bulky lymphadenopathy. Leuk Lymphoma. 2007; 48(10): 1931-1939.

6. Teeling JL, French RR, Cragg MS, van den Brakel J, Pluyter M, Huang $\mathrm{H}$, Chan C, Parren PW, Hack CE, Dechant M, Valerius T, van de Winkel JG, Glennie MJ. Characterization of new human CD20 monoclonal antibodies with potent cytolytic activity against non-Hodgkin lymphomas. Blood. 2004; 104(6): 1793-1800.

7. Teeling JL, Mackus WJ, Wiegman LJ, van den Brakel JH, Beers SA, French RR, van Meerten T, Ebeling S, Vink T, Slootstra JW, Parren PW, Glennie MJ, van de Winkel JG. The biological activity of human CD20 monoclonal antibodies is linked to unique epitopes on CD20. J Immunol. 2006; 177(1): 362-371.

8. Coiffier B, Lepretre S, Pedersen LM, Gadeberg O, Fredriksen H, van Oers MH, Wooldridge J, Kloczko J, Holowiecki J, Hellmann A, Walewski J, Flensburg M, Petersen J, Robak T. Safety and efficacy of ofatumumab, a fully human monoclonal anti-CD20 antibody, in patients with relapsed or refractory B-cell chronic lymphocytic leukemia: a phase 1-2 study. Blood. 2008; 111(3): 1094-1100.

9. Wierda WG, Kipps TJ, Mayer J, Stilgenbauer S, Williams CD, Hellmann A, Robak T, Furman RR, Hillmen P, Trneny M, Dyer MJ, Padmanabhan S, Piotrowska M, Kozak T, Chan G, Davis R, Losic N, Wilms J, Russell CA, Osterborg A. Ofatumumab as single-agent CD20 immunotherapy in fludarabine-refractory chronic lymphocytic leukemia. J Clin Oncol. 2010; 28(10): 1749-1755.

10. Moreno C, Montillo M, Panayiotidis P, Dimou M, Bloor A, Dupuis J, Schuh A, Norin S, Geisler C, Hillmen P, Doubek M, Trněný M, Obrtlikova P, Laurenti L, Stilgenbauer S, Smolej L, Ghia P, Cymbalista F, Jaeger U, Stamatopoulos K, Stavroyianni N, Carrington P, Zouabi H, Leblond V, Gomez-Garcia JC, Rubio M, Marasca R, Musuraca G, Rigacci L, Farina L, Paolini R, Pospisilova S, Kimby E, Bradley C, Montserrat E. Ofatumumab in poor-prognosis chronic lymphocytic leukemia: a phase IV, non-interventional, observational study from the European Research Initiative on Chronic Lymphocytic Leukemia. Haematologica. 2015; 100(4): 511-516.

11. Castro JE, Choi MY, Carvajal T, Almahasnah E, Chang J, James DF, Kipps TJ. Ofatumumab and high-dose methylprednisolone for the treatment of patients with relapsed or refractory chronic lymphocytic leukemia. Blood Cancer J. 2014; 4: e258.

12. Doubek M, Brychtova Y, Panovska A, Sebejova L, Stehlikova O, Chovancova J, Malcikova J, Smardova J, Plevova K, Volfova P, Trbusek M, Mraz M, Bakesova D, Trizuljak J, Hadrabova M, Obrtlikova P, Karban J, Smolej L, Oltova A, Jelinkova E, Pospisilova S, Mayer J. Ofatumumab added to dexamethasone in patients with relapsed or refractory chronic lymphocytic leukemia: Results from a phase II study. Am J Hematol. 2015; 90(5): 417-421.

13. Cortelezzi A, Sciumè M, Liberati AM, Vincenti D, Cuneo A, Reda G, Laurenti L, Zaja F, Marasca R, Chiarenza A, Gritti G, Orsucci L, Storti S, Angelucci E, Cascavilla N, Gobbi M, Mauro FR, Morabito F, Fabris S, Piciocchi A, Vignetti M, Neri A, Rossi D, Giannarelli D, Guarini A, Foà R. Bendamustine in combination with ofatumumab in relapsed or refractory chronic lymphocytic leukemia: a GIMEMA Multicenter Phase II Trial. Leukemia. 2014; 28(3): 642-648.

14. Costa LJ, Fanning SR, Stephenson J Jr, Afrin LB, Kistner-Griffin E, Bentz TA, Stuart RK. Sequential ofatumumab and lenalidomide for the treatment of relapsed and refractory chronic lymphocytic leukemia and small lymphocytic lymphoma. Leuk Lymphoma. 2015; 56(3): 645-649. 